Journal of Environmental Sciences (JES)

Faculty of Graduate Studies and Environmental Research, Ain Shams University

AbdulKarim, et al.

\title{
REVIEW OF IMPROVING ENERGY EFFICIENCY TECHNOLOGIES
}

\author{
Ahmad H. AbdulKarim ${ }^{(1)}$; Mohsen A. Tawfik ${ }^{(2)}$; Ahmed F. Hasan ${ }^{(3)}$ \\ and Ahmed T. Y.El-Awady ${ }^{(2)}$ \\ 1) Post Grad. Student, Faculty of Graduate Studies and Environmental \\ Research, Ain Shams University 2) Faculty of Graduate Studies and \\ Environmental Research, Ain Shams University 3) Faculty of Commerce, \\ Cairo University
}

\begin{abstract}
Energy Efficiency is central to achieving the interrelated economic, social and environmental goals of sustainable development. Improving Energy Efficiency is about using technology that requires less energy to perform the same function plus the share of renewables in final energy consumption. and it goes beyond energy conservation behavior which results in the use of less energy

This paper focuses on the deployments of improving Energy efficiency as important infrastructure for smart environment. Home energy management systems employ automated technologies to manage and reduce residential energy use and cost, as well as make energy reductions through energy efficiency measures more visible to the customer, and extend energy management systems to Internet of things applications. We first review energy management systems and Internet of things technologies. Then, we investigate the role of Cost Benefit Analysis in supporting decision-making processes in the context of projects related to home automation application.

Keywords: Energy Efficiency, Home automation, Energy Management System, Internet of things, Cost benefit analysis.
\end{abstract}


Journal of Environmental Sciences (JES)

Faculty of Graduate Studies and Environmental Research, Ain Shams University

AbdulKarim. et al.

\section{INTRODUCTION}

Efficient energy consumption and generation is a key factor to world ambitious goals for sustainable development and activities related to environmental Impacts and climate shifting. It is becoming increasingly clear that energy efficiency can bring many significant economic, environmental and social benefits. Yet it is also clear that huge energy efficiency potential remains untapped. While energy efficiency is improving, its impact on global energy use is being overwhelmed by increasing economic activity across all sectors.

With regard to Energy efficiency, we can define Energy intensity as it is a measure of the amount of energy used to produce a unit of output. It measures how much a bit of energy benefits the economy. This value is calculated by taking the ratio of total primary energy use (all of the fuels and flows that a country uses to get energy) to Gross Domestic Product (GDP) (total money made in a country). This quantity is used to indicate how effectively a certain economy is using their fuels and flows. When a country reduces wasted energy, it becomes more efficient, this lowers its Energy intensity. Low energy intensity indicates a lower price or cost of converting energy into GDP (IEA, 2018).

The energy intensity indicator used is primary energy demand per unit of global (Gross Domestic Product) GDP, i.e. the amount of energy the global economy uses (before it is converted into end-use fuels such as electricity and gasoline) to produce one unit of economic output. 
Changes in global primary energy intensity are not solely an indication of energy efficiency improvements. They are also influenced by factors such as the movement of economic activity away from energy-intensive heavy industries towards less energy-intensive service sectors (Shanker, 2018).

The direction of global energy demand will hinge critically on how quickly technologies more efficient than those available today are developed, commercialized and used. The world could make vast improvements to efficiency now, however, by adopting technologies already widely available.

Regarding Sustainable Development Goals, the world is not currently on track to meet Sustainable Development Goal 7 (SDG7), which calls for ensuring "access to affordable, reliable, sustainable and modern energy for all" by 2030. Current progress falls short on all four of the SDG7 targets, which encompass universal access to electricity as well as clean fuels and technologies for cooking, and call for a doubling of the rate of improvement of energy efficiency, plus a substantial increase in the share of renewables in the global energy mix (UN, 2018).

The conventional energy sources become not sufficient to meet the dayto-day increasing power demand. So, renewable sources of energy are utilized along with conventional systems to meet that demand. However, the successful realization of such deployment would require Update energy and power sector strategies to reflect the growing cost. The present strategy of Egypt, developed in 2014, does not reflect the rapid economic and Vol.(50); Iss.(8); No.(5); Aug. 2021 
Journal of Environmental Sciences (JES)

Faculty of Graduate Studies and Environmental Research, Ain Shams University

AbdulKarim. et al.

technological changes taking place at the national and regional levels (IRENA, 2018).

In order to tackle the increasing electricity demand, a number of solutions for efficient energy consumption and new power distribution models have to be evaluated. Moreover, innovative, energy-aware, flexible and user-centric solutions, able to provide interactive energy monitoring, intelligent control and power demand balancing at residential household (IRENA, 2018).

Because of the rapid rise of the population density inside urban environments, substructures and services have been needed to supply the requirements of the citizens. Humanity is faced with a new type of Paradigm, generally called the "smart city - smart Home" paradigm. Different classical objects are called Things and have been offered smart communication Possibilities in order to transmit data coming from a large Spectrum of sensors. Accordingly, there has been a remarkable growth of digital devices, such as sensors, actuators, smartphones and smart appliances which drive to vast commercial objectives of the Internet of Things (IoT).

Monitoring temperature, humidity, Noise and pollution levels have become a common feature to homes, offices, cars and streets. The issues that have been identified in the new technological era range from Standards, communication protocols, but also human communication Interfaces. 
The beauty of the way in which smart homes save energy is the elegance of it. They do not try to restrict your energy consumption nor do they try to force you into doing so yourself. Instead, they keep track of your lifestyle and try to find ways not to spend energy when you do not need it. Furthermore, they are designed to make the most out of available energy. If you factor in all of that, it is no surprise that smart, homes can sometimes save up to $30-40 \%$ of energy.

In this paper, we describe Energy management systems in the next section. Then we review Energy efficiency with IoT and its major components. In the fourth section, we briefly discuss Home Energy efficiency Cost Benefit Analysis and SOWT analysis.

\section{ENERGY MANAGEMENT SYSTEMS}

Energy management systems (EMS) monitor, control, and optimize the generation, transport and use of energy. Early EMS operations were based on analogue meters with fast and easy-to-understand information, though limited in scope and application.

There are many existing drivers for the installation of meters and sensors in buildings, but the overriding driver is usually to enable better management of energy within the building and ultimately identifying and achieving potential energy and cost savings and to verify savings that have been achieved. However, there is a considerable overlap between these 
Journal of Environmental Sciences (JES)

Faculty of Graduate Studies and Environmental Research, Ain Shams University

AbdulKarim. et al.

drivers and often it is difficult to assess which driver takes precedence over others (Ahmad, 2016). 
- Mitigating climate change and enhancing energy efficiency

- Feedback on energy consumption and cost reduction

- Compliance with regulations and legislations

- Social responsibility

EMS also has age-long application in the residential sector. The use of workable night thermostat as a form of automated energy control dates back to the early 1900's (Liu, 2016). However, energy management became a real concern in the 1970s, especially with the multiple energy crises, increasing energy cost, and the idea of energy conservation. Early EMS operations were based on analogue meters with skimpy, but fast, easy to understand information. They were however limited in scope and application (Horton, 1986). Fig. 1 shows historical evolution of developing Energy management systems.

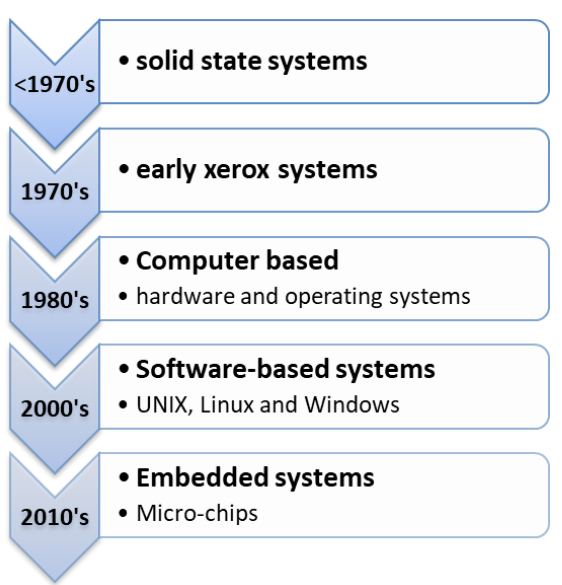

Fig1: Energy Management system evolution 
Journal of Environmental Sciences (JES)

Faculty of Graduate Studies and Environmental Research, Ain Shams University

AbdulKarim. et al.

The technological evolutions in the 1980s changed the EMS, particularly with the coming of computer-based technologies (mostly with hardware and operating systems). By the early 2000s, software-based systems such as UNIX, Linux and Windows have dominated EMS technologies.

Presently, embedded systems technologies have taken over. The old, bulky, space-consuming solid-state technologies have given way to more compact, small and efficient embedded or chip-based systems. The conversion of theoretical considerations into effective and robust algorithms accounts for the growth and effectiveness of the EMS.

In principle, EMS is also a matured technology in the residential sector but it is mostly not named like that. The system has grown over the years into other fields such as security systems, entertainment, energy-efficient appliances, Heating, Ventilation And Cooling (HVAC) control, e-health (healthcare supported with electronics) and remote controls. Automation of the distribution network operation to facilitate and incorporate the emerging Smart Grid functionalities has gained attention just recently (Calvillo, 2016). This also brings EMS operations closer to the customer at home and benefits of smart metering as follows in next sections.

\subsection{Home Energy Management System (HEMS)}

The exponential growth in EMS vendors underscores the importance of the technology to the residential sector. In spite of the hundreds of products, HEMS can be broadly grouped under the following functionalities: 
1. Informative systems: They enable a one-way communication providing real-time and historical information about energy use in various graphical forms (bar graphs, pie charts, etc.) to the users.

2. Automated systems: They provide a two-way flow of information between a home gateway and domestic appliances.

3. Integrated systems: They have all the features of the information, automated and control systems, but also include direct control of devices by third parties. The possibility for forecasting (e.g. price) and scheduling of loads and generations at household levels are present in some products.

The integrated framework for developing future home energy management system. It takes into account the building itself, the type of building, year it was built and the orientation. Also important are the kind of residence in that house: elderly, large family, students or singles. Secondly, the connection of the HEMS to the utility is very important for its integration and sustainability. It enables residential demand response applications.

In the third place is the local installation at the customers' site. Are there smart meters, sensors and appliances and how are they integrated? Are there distribution generators at the customer site and how can that be coupled with the system?

Fourth is the energy management principle to be implemented (AsareBediako, 2012). 
Regulatory, social-economic and environmental concerns which are often overlooked during the design stages are worth considering if the HEMS solution will be sustainable.

\subsection{Electricity Smart Metering}

Energy management system classified into three main categories: different building performance parameters, occupants comfort perception and machinery characteristics.

Since the introduction of electricity distribution grids, there has been a demand for devices to measure the energy consumption in order to assist suppliers for distributing, pricing and monitoring their service. Time-Driven electricity metering is a process that measures the amount of electric energy produced or consumed during a certain period of time, supplying the relevant information about the behavior of the power system in the recent past (Simonov, 2014).

Electricity meters operate by continuously sensing the instantaneous values of current and voltage to provide a measurement of energy used (and possibly power demand). Fig. 2 describes the oldest and most common type of electricity meter is the electromechanical watt-hour. It is composed of an electrically conductive metal disc whose rotational speed is proportional to the power passing through the meter (Kara, 2011). 

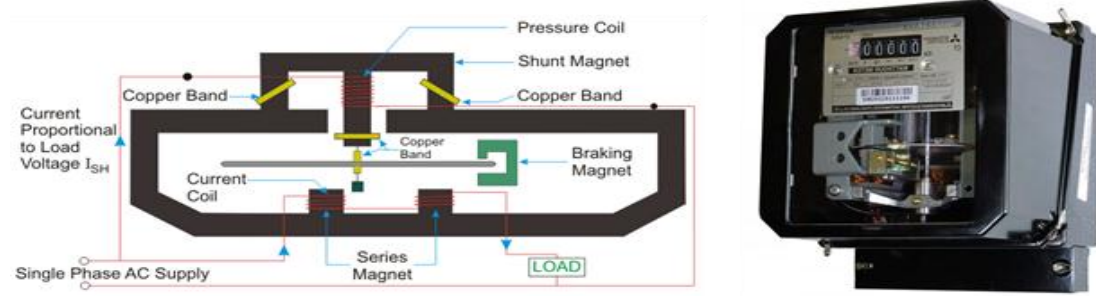

Fig. 2. the electromechanical watt-hour meter (Electrical4U, 2019)

The first attempts at metering automatization, or Automated Meter Reading (AMR), allowed utilities to remotely read the consumption records and basic status information from customers premises. Due to its one-way communication system, AMR is limited to remote reading and cannot run additional applications, which prompted utilities to move towards the Smart Metering or Advanced Metering Infrastructure (AMI) (Choi, 2009). In Table 1 some differences of smart meters in functionality and stakeholder's contribution.

Table 1: Evolution of Smart Metering

\begin{tabular}{|c|c|c|}
\hline $\begin{array}{c}\text { SMART METER } \\
\text { SYSTEM }\end{array}$ & FUNCTIONALITY & STAKEHOLDERS \\
\hline $\begin{array}{l}\text { One way } \\
\text { Automated meter Reading } \\
\text { AMR* }\end{array}$ & $\begin{array}{l}\text { Automated monthly read } \\
\text { One way outage detection } \\
\text { Load profiling } \\
\text { Tamper detection }\end{array}$ & $\begin{array}{l}\text { Billing and accounting } \\
\text { Customers }\end{array}$ \\
\hline AMR Plus & $\begin{array}{c}\text { Daily or on demand reads } \\
\text { Hourly interval data } \\
\text { Outage notification }\end{array}$ & $\begin{array}{l}\text { Billing and accounting } \\
\text { Information technology }\end{array}$ \\
\hline $\begin{array}{c}\text { Two way } \\
\text { Advanced Metering } \\
\text { Infrastructure } \\
\text { AMI* }\end{array}$ & $\begin{array}{l}\text { Integrated service switch } \\
\text { Time based rates } \\
\text { Remote meter programming } \\
\text { Power quality }\end{array}$ & $\begin{array}{l}\text { Billing and accounting } \\
\text { Information technology } \\
\text { Customers service }\end{array}$ \\
\hline
\end{tabular}

*AMR: Automated Meter Reading *AMI: Advanced Metering Infrastructure

Vol.(50); Iss.(8); No.(5); Aug. 2021

ISSN 1110-0826

Online ISSN 2636-3178 
AMI is the system to add the communication link to the smart grid network. AMI includes bidirectional data flow between end users and utilities. AMI provides intelligent management, better maintenance, easier and proper additions and replacement of utility assets which results in better power quality (Barai, 2015).

When an Advanced Metering Infrastructure (AMI) is in place, smart meter can measure and record actual power usage during a day at certain time interval. These collected data are sent to a central data management system over a secure network via wired or wireless communication.

Implementation of smart metering will provide a number of benefits to the consumer, to the utility and to our society as follows (Hydro One, 2013) (Alahakoon, 2016) (Uribe-Pérez, 2016):

\section{1) Benefits to the customer:}

- Consumers get more information about their energy usage. This will provide energy efficiency gains for both the consumer and the industry.

- Increased knowledge of quality of delivery and more detailed feedback on energy use.

- Bills are based on actual consumption.

- Customer can adjust their habits to use more during off peak hours to lower electric bills.

- Power outages are reduced.

- Switching and moving are easily facilitated. 
- The necessity of bill estimation is reduced.

- No need to provide access to utility people for taking reading of meters located indoors.

\section{2) Benefits to the utilities:}

- Demand peaks are reduced.

- Remote controlling enables better management of billing and other consumer related issues.

- Automated and remote meter reading.

- Electric systems are monitored more quickly.

- Enabling more efficient use of power resources

- Power outages are reduced.

- Enabling dynamic pricing.

- A voiding building of new power plants.

- Optimizing income with existing resources.

- Increased information on low voltage network.

- Freeing up experienced staff for other high priority areas to better serve the customers.

- Operational costs are reduced.

\section{3) Benefits to the environment:}

- Smart Meters communicate directly with the utility, eliminating the need to put utility trucks out on the street. 
Journal of Environmental Sciences (JES)

Faculty of Graduate Studies and Environmental Research, Ain Shams University

AbdulKarim. et al.

- Smart meters prevent the need for new power plants by contributing to the proper distribution of existing power usage, and as a result reduce pollution.

- Smart meters indirectly reduce the emission of greenhouse gas from existing power plants.

\section{Energy Efficiency with Internet of Things}

Today the Internet has become ubiquitous, has touched almost every corner of the globe, and is affecting human life in unimaginable ways. However, the journey is far from over. We are now entering an era of even more pervasive connectivity where a very wide variety of appliances will be connected to the web. We are entering an era of the "Internet of Things" (IoT) (Atzori, 2017). IoT is extension of current internet to provide communication, connection, and internetworking between various devices or physical objects also known as "Things" (Patel, 2016). This term has been defined by different authors in many different ways. Let us look at two of the most popular definitions. the Internet of Things as simply an interaction between the physical and digital worlds (Yang, 2014). The digital world interacts with the physical world using a plethora of sensors and actuators. Another definition the Internet of Things as a paradigm in which computing and networking capabilities are embedded in any kind of conceivable object (Dorsemaine, 2015). 
In common parlance, the Internet of Things refers to a new kind of world where almost all the devices and appliances that we use are connected to a network. Fig. 3 shows this network structure components which We can use them collaboratively to achieve complex tasks that require a high degree of intelligence (Suresh, 2014).

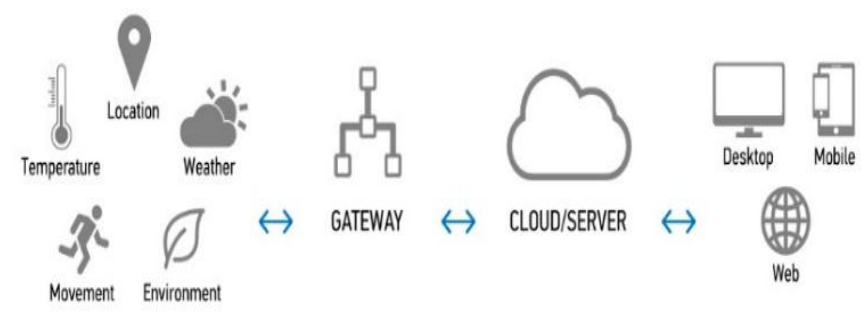

Fig. 3. Internet of Things (IOT) System Structure

For this intelligence and interconnection, IoT devices are equipped with embedded sensors, actuators, processors, and transceivers. IoT is not a single technology; rather it is an agglomeration of various technologies that work together in tandem (Lamba, 2017).

The Internet of Things is rarely discussed without the conversation steering to data and the new Data Economy. The intelligence and value from an IoT system is based on what can be learned from the data. Sensors are the source of IoT data. The ability to collect data coming from new end points, will increase the amount of available data. Data from IoT devices are delivered in real-time, can uniquely identify "things", and can continuously collect/monitor "things" without human intervention. Enablers for the rise 
Journal of Environmental Sciences (JES)

Faculty of Graduate Studies and Environmental Research, Ain Shams University

AbdulKarim. et al.

of IoT include: cheap sensors, cheap bandwidth, cheap processing and big data (Opher, 2016).

Sensors and actuators are devices, which help in interacting with the physical environment. The data collected by the sensors has to be stored and processed intelligently in order to derive useful inferences from it. Note that we broadly define the term sensor; a mobile phone or even a microwave oven can count as a sensor as long as it provides inputs about its current state (internal state + environment) (García, 2017). An actuator is a device that is used to effect a change in the environment such as the temperature controller of an air conditioner (Serra, 2014).

The Internet of Things finds various applications in health care, fitness, education, entertainment, social life, energy conservation, environment monitoring, home automation, and transport systems. IoT technologies have significantly been able to reduce human effort, improve energy efficiency and improve the quality of life. In next sections, we cover basic architecture of IoT and most major technologies spanning from sensors to applications. Then we discuss the relation between IoT and Embedded systems in different prospective and comparison of supported technologies.

3.1 Architecture of IoT: The Internet of Things (IoT) general architecture for any system consists of three stages: physical, communication, and application. The first layer features multiple-sensor network that evaluates physical activities. Also included in the physical layer is another monitoring network that consists of in-house sensors and actuators to maintain air 254 Vol.(50); Iss.(8); No.(5); Aug. 2021 ISSN 1110-0826 Online ISSN 2636-3178 
Journal of Environmental Sciences (JES)

Faculty of Graduate Studies and Environmental Research, Ain Shams University

AbdulKarim, et al

quality, temperature, and to analyze and determine any hazardous conditions for the user. The second layer includes Operational Technology devices that collect the information gathered by the sensors, translate it into meaningful data streams and transfer them to a back-end destination. The third layer is where data is received, stored, and processed using cloud-based data analysis engines and machine learning mechanisms. The resulting insights can be used to recommend the proper service for each specific situation or applied in further research or management purposes (Uckelmann, 2011).

There is no single consensus on architecture for IoT, which is agreed universally. Different architectures have been proposed by different researchers.

The most basic architecture is a three-layer architecture. It was introduced in the early stages of research in this area. It has three layers, namely, the perception, network, and application layers (Said, 2013).

(i) The perception layer is the physical layer, it is like the facial skin and the five sense organs of loT, which is mainly identifying objects, gathering information. which has sensors for sensing and gathering information about the environment. It senses some physical parameters or identifies smart objects in the environment. The Perception Layer includes bar code labels and readers, RFID tags and reader-writers, camera, GPS, sensors, terminals, and sensor network. The perception layer is the lowest layer of the conventional architecture of IoT and also called the recognition layer (Miao, 2010). 
Journal of Environmental Sciences (JES)

Faculty of Graduate Studies and Environmental Research, Ain Shams University

AbdulKarim. et al.

(ii) The network layer is acting like the brain of loT, its main function is transmitting and processing information. It is responsible for connecting to other smart things, network devices, and servers. Its features are also used for transmitting and processing sensor data. This layer's main responsibility is to help and secure data transmission between the application and perception layer. This layer also ensures unique addressing and routing abilities to the unified integration of uncountable devices in a single cooperative network. Various types of technologies are contributed for this phenomenon such as wired, wireless and satellite.

(iii) The application layer is a combination of loT's social division and industry demand, to realize the extensive intellectualization. The Application Layer is the deep convergence of loT and industry technology, combined with industry needs to realize the intellectualized industry, similar to person's social division of labor, eventually form human society. It is responsible for delivering application specific services to the user. It defines various applications in which the Internet of Things can be deployed, for example, smart homes, smart cities, and smart health.

3.2 Sensors and Actuators: All IoT applications need to have one or more sensors to collect data from the environment. Sensors are essential components of smart objects. One of the most important aspects of the Internet of Things is context awareness (Perera, 2014), which is not possible without sensor technology. A sensor is a device (typically electronic) that 256

Vol.(50); Iss.(8); No.(5); Aug. 2021 ISSN $1110-0826$ Online ISSN 2636-3178 
detects events or changes in its physical environment (e.g., temperature, sound, heat, pressure, flow, magnetism, motion, and chemical and biochemical parameters) and provides a corresponding output. Most sensors take analog inputs and deliver digital, often electrical outputs. Because the sensing element, on its own, typically produces analog output, an analog-todigital convertor is often required (Saeid, 2017).

Sensors may be very simple with a core function to collect and transmit data or smart by providing additional functionality to filter duplicate data and only notify the IoT gateway when very specific conditions are met. This requires some programing logic to be present on the sensor itself. In this case, an IoT sensing device requires at least three elements sensor(s), microcontrollers, and connectivity to send data to IoT gateway (Kumar, 2018).

An actuator is a type of motor that is responsible for controlling or taking action in a system. It takes a source of data or energy (e.g., hydraulic fluid pressure, other sources of power) and converts the data/energy to motion to control a system.

As mentioned, sensors are responsible to sense changes in their surroundings, collect relevant data, and make such data available to monitoring systems. Collecting and displaying data by a monitoring system is useless unless such data is translated into intelligence that can be used to control or govern an environment before a service is impacted. Actuators use sensor-collected and analyzed data as well as other types of data Vol.(50); Iss.(8); No.(5); Aug. 2021 
Journal of Environmental Sciences (JES)

Faculty of Graduate Studies and Environmental Research, Ain Shams University

AbdulKarim. et al.

intelligence to control IoT systems. For example, shutting down gas flow when the measured pressure is below a certain threshold.

3.3 Communication Protocols: As the Internet of Things is growing very rapidly, there are a large number of heterogeneous smart devices connecting to the Internet. IoT devices are battery powered, with minimal compute and storage resources. Because of their constrained nature, there are various communication challenges involved,

- Addressing and identification: since millions of smart things will be connected to the Internet, they will have to be identified through a unique address, on the basis of which they communicate with each other.

- Low power communication: communication of data between devices is a power consuming task, specially, wireless communication. Therefore, we need a solution that facilitates communication with low power consumption (Dragomir, 2016).

- Routing protocols with low memory requirement and efficient communication patterns.

- High speed and non-lossy communication.

- Mobility of smart things.

Based on the architectures mentioned earlier, IoT can be realized with several enabling communication technologies. In the perception layer, the main function is to identify and track objects. To achieve this function, the following technologies can be implemented: 
Journal of Environmental Sciences (JES)

Faculty of Graduate Studies and Environmental Research, Ain Shams University

AbdulKarim, et al.

\section{(i) Radio Frequency Identification (RFID)}

RFID is an identification technology in which an RFID tag (a small chip with an antenna) carries data, which is read by a RFID reader. Each RFID tag is attached in an object and has its unique identification number. A RFID reader can identify an object and obtain the corresponding information by querying to the attached RFID tag through appropriate signals. The tag transmits the data stored in it via radio waves.

It is similar to bar code technology. But unlike a traditional bar code, it does not require line of sight communication between the tag and the reader and can identify itself from a distance even without a human operator. The range of RFID varies with the frequency. It can go up to hundreds of meters (Finkenzeller, 2003).

\section{(ii) Near Field Communication (NFC)}

NFC is a very short-range wireless communication technology, through which mobile devices can interact with each other over a distance of few centimeters only. All types of data can be transferred between two NFC enabled devices in seconds by bringing them close to each other. This technology is based on RFID. It uses variations in the magnetic field to communicate data between two NFC enabled devices (Coskun,2013).

\section{(iii) Wireless Sensor Networks (WSN)}

WSN is a wireless network that consists of base stations and numbers of nodes (wireless sensors). These networks are used to monitor physical or environmental conditions like sound, pressure, temperature and coVol.(50); Iss.(8); No.(5); Aug. 2021 
operatively pass data through the network to a main location (Kocakulak, 2017).

Wireless Sensor Networks (WSN) Based on IP for Smart Objects. Many times, data from a single sensor is not useful in monitoring large areas and complex activities. Different sensor nodes need to interact with each other wirelessly.

\section{(iv) Barcode \& QR Code}

Barcode is a symbol attached to every object that could be read only by a barcode scanner. Barcodes can be implemented simply. There are no technological difficulties in implementing or using a Barcode. An updated 2D matrix representation of barcode is the QR Code.

After reviewing perception layer technologies, the second layer is Network layer. The network layer is used to determine routing, and provide data transmission support through integrated heterogeneous networks. In the following, some protocols that can enable the reliable and secure communication in IoT are presented.

\section{(v)BLUETOOTH:}

One of the most broadly used wireless technologies of short-range is Bluetooth. You can quickly get Bluetooth apps that offer you wearable technology for pairing up with the smart gadgets. Bluetooth is a short-range RF technology aimed at facilitating communication of electronic devices between each other and with the Internet, allowing for data synchronization 
Journal of Environmental Sciences (JES)

Faculty of Graduate Studies and Environmental Research, Ain Shams University

AbdulKarim, et al.

that is transparent to the user. Supported devices include PCs, laptops, keyboards, cell phones, and consumer products (Ghodake, 2018).

\section{(vi) ZIGBEE:}

Zigbee is a low-cost, low-power, wireless mesh network standard targeted at battery-powered devices in wireless control and monitoring applications. It is based on the IEEE 802.15.4 communication protocol standard and is used for personal area networks. Zigbee delivers low-latency communication. Zigbee chips are typically integrated with radios and with microcontrollers (Ghodake, 2018).

(iii) Wi-Fi

For IoT integration, $\mathrm{WiFi}$ is a favored choice according to many electronic designers. It is because of the infrastructure it bears. It has quick data transfer rates along with the aptitude to control a large quantity of data. The widespread WiFi standard 802.11 presents you the ability to transfer hundreds of megabits in only one second. The only own drawback of this IoT protocol is it can consume excessive power for some of the IoT Application (Sundaram, 2016).

3.4 IoT Evolution Towards Energy Efficiency: The Internet revolution led to the interconnection between people. The next revolution indicates the interconnection between objects to create a smart Environment. Smart Environment is the one that is able to acquire and apply knowledge about an environment and also able to adapt to its inhabitants in order to improve their experience in that environment. IoT can be considered as the 
foundation of Smart Environment that is a small world where all kind of smart devices are continuously working to make inhabitants' lives more comfortable (Gurkan, 2017).

Garter's Information Technology Hype Cycle for the year 2018 also reveals that IoT platform tops the chart with respect to peak inflated expectations; that had initiated through an innovation trigger and has reached the maximum level of expectation, where the dependency rate and increased expectations persuade researches for newer developments. Fig. 4. depicts the Emerging technologies according to Gartner's Hype Cycle report.

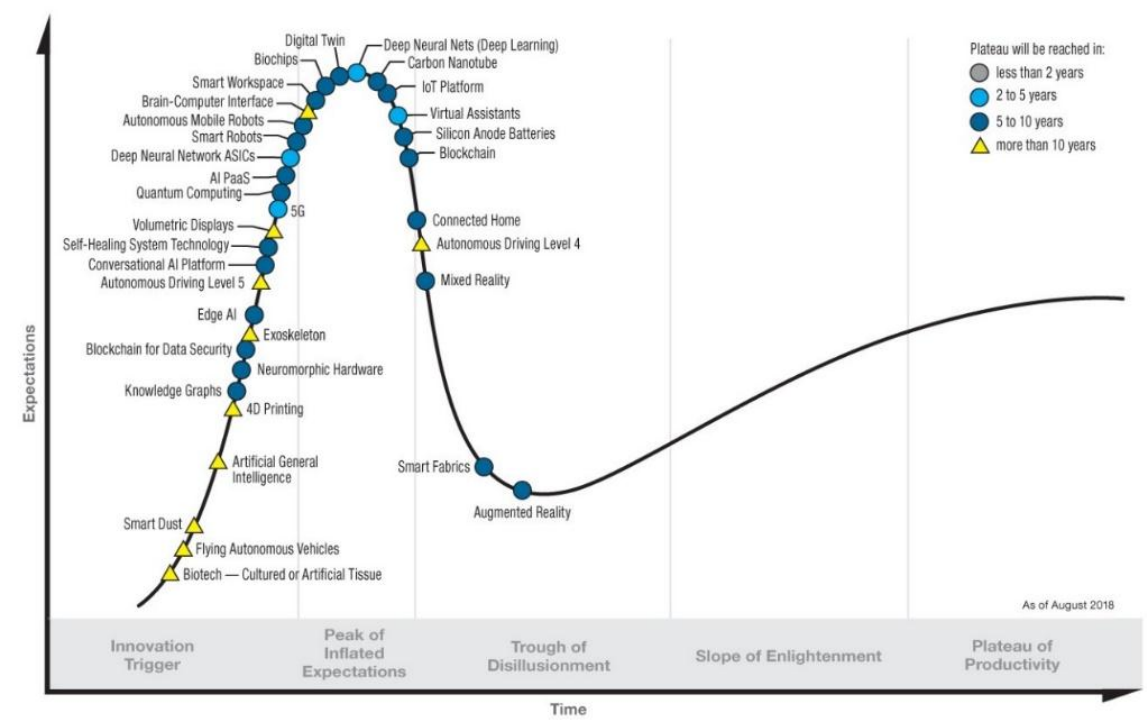

Fig 4 . Emerging technologies [Gartner hype cycle 2018] 
Journal of Environmental Sciences (JES)

Faculty of Graduate Studies and Environmental Research, Ain Shams University

AbdulKarim, et al.

As technology continues to evolve, the IoT will just become a more significant part of consumer's lives. It is because of the added convenience and personalization that these devices can provide. IoT technology can support the ageing population, vulnerable people and people with chronic conditions. Integrating the Internet of Things does benefit different businesses, but there is no denying that the Internet of Things will also benefit the consumers as follows.

1. Environmental benefits: Environmental parameters such as temperature and humidity are important for application such as agricultural production (Yang, 2017). There are a range of sensors that measure air quality and warn users through apps on their smartphones when the air is at dangerous levels, or likely to cause asthma. This is not only helpful for the user, but can also raise awareness of pollution and high emissions in populated areas. Similar devices are also used for working with radiation and miners.

Smart homes have become the state of the art in the reduction and monitoring of energy usage within a residential setting. Leaving lights on, heating a house that's empty or heating up water that no one is going to use are all big wastes of energy. But smart and connected homes can prevent unnecessary energy use. Emerging threats such as climate change, global warming and volatility in energy prices have fueled the interest in smart systems and IoT. The use of energy efficient devices and innovative technologies has made it possible to reduce energy consumption, which is 
Journal of Environmental Sciences (JES)

Faculty of Graduate Studies and Environmental Research, Ain Shams University

AbdulKarim. et al.

vital in order to meet growing electricity demand and utilization. The benefit of energy efficiency has become possible through the implementation of four services:

1) monitoring the information on energy consumption,

2) controlling the consumption patterns through remote devices and direct control,

3) management of the service, aimed at achieving efficiency and optimization, and

4) consultancy. On a nationwide scale.

Research effort has already been invested in studying the implementation of wind, solar, biomass and geothermal energy in the smart home energy systems. The embeddedness of renewable systems into smart houses could speed up the outcome of wise electricity and demand management.

2. Financial benefit: The financial benefits of IoT smart Energy systems are typically associated with the environmental and health-related benefits. While in the long-term perspective the utilization of energy saving devices leads to environmental sustainability, the immediate benefit of efficient energy consumption management is the reduction of electricity expenses. The financial benefits can be realized in two ways. First, the use of smart electric appliances and smart meters leads to higher awareness of the consumption habits, by regular monitoring of 
the energy use. Second, the transparency of the energy consumption makes it possible to compare tariffs against other energy providers.

IoT's adoption in industries such as agriculture, energy, manufacturing, and urban development promises to return economic gains. Waste management (of time or resources) can boost cost savings and industrial productivity. New markets for data promise to expand opportunities to monetize the inputs and outputs of IoT deployments.

3. Social benefits: Social life and entertainment play an important role in an individual's life. Many applications have been developed, which keep track of such human activities. The term "opportunistic IoT" refers to information sharing among opportunistic devices (devices that seek to make contact with other devices) based on movement and availability of contacts in the vicinity. Personal devices such as tablets, wearables, and mobile phones have sensing and short-range communication capabilities. People can find and interact with each other when there is a common purpose.

Therefore, IoT appliances have proven really beneficial in the health and wellness domains. Many wearable devices are being developed, which monitor a person's health condition.

3.5 Relation Between Embedded Systems and IoT Technologies: The embedded system is no longer a strange concept now. With the microprocessor chip as the core, it was born with the emergence of the microprocessor. Through 30 years' development, the embedded system has 
Journal of Environmental Sciences (JES)

Faculty of Graduate Studies and Environmental Research, Ain Shams University

AbdulKarim. et al.

become a complex system from a simple system. The embedded system can deal with complex application rather than controlling the input and output. With the development of chip technology and interface technology, there are a variety of embedded systems. In order to satisfy the growing demands of users, the system becomes increasingly more complicated and the functions are also more, including mobile phone, MP4, electrical vehicle, etc. Although the embedded system has entered people's daily life, there is no a unified definition of the embedded system yet through extensive discussion. Currently, the definition that is generally accepted at home is: the embedded system refers to a specified computer system that adapts to the application system's strict requirement for function, reliability, cost, volume, and power consumption with the application as the center and computer technology as the foundation, whose software and hardware are scalable.

The Internet of Things means "the Internet that links things". It has two meanings: first, the core and foundation of the Internet of things is still Internet. It is the extended and expanded network on the basis of Internet; second, the extension and expansion of the user terminal is between any object for information exchange and communication. Or think that: The Internet of things is wireless sensor network; the Internet of things is RFID network. The above definitions analyze and define the Internet of things from the perspective of Internet, so as to get the result: Internet is a subset of 
Internet of things; one of the support technologies of Internet of things is network and communication technology (Asare-Bediako, 2012).

From the perspective of definition, the Internet of things emphasizes that the equipment in the Internet of things have perception, calculation, execution, coordination and communication ability and can provide services; the embedded system emphasizes the special computing system that is embedded into the host object. Its functions and services are relatively simple. The function of the embedded system is a subset of the function of the Internet of things, but the difference between them will be increasingly smaller. The simple embedded system is quite different from the equipment or things in the definition of the Internet of things and the functions are inferior to the equipment or things in the Internet of things. But with the development of the embedded system, some complex embedded systems that have appeared currently (such as smart mobile phone) basically meet the requirements of the equipment or things in the definition of the Internet of things. 
Journal of Environmental Sciences (JES)

Faculty of Graduate Studies and Environmental Research, Ain Shams University

AbdulKarim. et al.

Table 2: Comparison Table of Support Technology (Asare-Bediako, 2012)

\begin{tabular}{||c|c|c|}
\hline TECHNOLOGY & $\begin{array}{c}\text { INTERNET OF } \\
\text { THINGS }\end{array}$ & $\begin{array}{c}\text { EMBEDDED } \\
\text { SYSTEM }\end{array}$ \\
\hline \hline $\begin{array}{c}\text { Radio frequency identification } \\
\text { technology (RFID) }\end{array}$ & Essential & Optional \\
\hline Electronic technique & Essential & Essential \\
\hline Sensor technology & Essential & Optional \\
\hline Semiconductor technology & Essential & Essential \\
\hline Communication technology & Essential & Optional \\
\hline $\begin{array}{c}\text { Intelligent Computing } \\
\text { Technology }\end{array}$ & Essential & Optional \\
\hline Automatic control technology & Optional & Optional \\
\hline Software Testing Technology & Essential & Essential \\
\hline \hline
\end{tabular}

From the perspective of technology, the embedded system is the product of the combination of advanced computer technology, semiconductor technology and electronic technology and the specific application in various industries. According to different applications, the embedded system can be used in many other technologies, such as: communication technology, sensor technology, intelligent information processing technology, automatic control technology, etc. the Internet of things and embedded system both are the comprehensive technology that integrates various technologies and the technologies are roughly the same. Table 2 shows a comparison between essential and optional support technologies for both IoT and Embedded systems for different types of applications. 
Journal of Environmental Sciences (JES)

Faculty of Graduate Studies and Environmental Research, Ain Shams University

AbdulKarim, et al.

From the angle of philosophy, the "things" in Internet of things refers to the things that are not limited to the physical world. It also includes the virtual goods and event associated with the things. So, the "things" in IoT can be defined as the entity that exist truly and can be identified in time and space or the virtual entity. The development process of the IoT: the microprocessor has been embedded in many daily objects currently. The objects make continuous innovations and increase new features and communication interface on the original basis.

Embedded microprocessor and microcontroller technologies are an important subject for researching implementation of small low-power embedded autonomous systems. Thus, they are in focus for the future IoT and smart home areas. The IoT requires sensors and actuators to form the link between the physical and digital worlds. A sensor converts a physical state into an analogue or digital signal, while an actuator turns a digital signal into some physical effect. The next step in the IoT architecture is the computing system which processes or generates the digital signals. IoT product is a system, not a component. So, when planning any element of your design, it's important to take into consideration the full stack of hardware, software, and infrastructure.

In a word, the change of Internet from the network that connects computer to the network that connects objects (namely Internet of things) owns to the seamless access of the embedded microprocessor, sensor, executor, object network interface combination. The "things" in Internet of Vol.(50); Iss.(8); No.(5); Aug. 2021 
Journal of Environmental Sciences (JES)

Faculty of Graduate Studies and Environmental Research, Ain Shams University

AbdulKarim. et al.

things is divided into two parts: hardware and software. The hardware part refers to the part outside of the inherent and actual substance of "things" itself.

it can be drawn that: the composition of embedded system is the same as the "things" in Internet of things. But compared to the embedded system, the complexity of hardware and software in Internet of things is higher and the modules are more, because the functions that shall be satisfied are more. When some current embedded systems improve the network communication ability of system equipment and add the intelligent information processing technology, these systems can be applied to the Internet of things. Therefore, the "things" in Internet of things can be considered as the outcome that the embedded system develops to certain stage.

To sum up, the integration of related technology of embedded system and the Internet of things produces a lot of new products and services, improves people's living quality and level and makes people enjoy unprecedented convenience.

\section{Home Energy Efficiency Cost-Benefit Analysis:}

The literature on the economic impact of energy the concept of economic savings through energy efficiency had entered the climate policy discussion as "co-benefits" to climate mitigation action. Energy cost can be reduced in many ways. By understanding the consumption behavior of each load in a building. Heating, Ventilation And Cooling (HVAC) consumed the most energy of a commercial building followed by lighting, refrigeration 
and office equipment. By choosing to retrofit and improve HVAC energy efficiency would lower the energy cost of the building.

The growth of the Smart home market is driven by various factors, such as rise in the need for energy- saving and low carbon emission solutions; cost reduction measures enabled by market; rapid proliferation of smartphones and smart gadgets; a large base of internet users and increased adoption of smart devices; high importance of home monitoring from remote locations; and widespread concern about safety, security, and smart home market.

Several ways exist for economic evaluation of smart home projects. Global Home Automation Systems market provides comprehensive analysis of the market by considering key market segmentation. Which means Divide your market into micro markets, or segments, based on segmentation bases or variables.

Moreover, many studies suggested the application of a Cost-Benefit Analysis (CBA) methodology to compare different energy scenarios and set the minimum energy requirements for buildings. CBA is a simple tool for evaluating a smart home investment. Its value lies not just in the result it provides but also in how it requires one to define and quantify the expected costs and benefits. Often it is this analytical discipline, rather than the result itself, that is most informative. 
Journal of Environmental Sciences (JES)

Faculty of Graduate Studies and Environmental Research, Ain Shams University

AbdulKarim. et al.

Also, to make the most of what you've got, Strengths, Weakness, Opportunities and Threats (SWOT) Analysis is a useful technique to map out the present Strengths, Weakness, Opportunities and Threats of home automation and improving energy efficiency technologies.

4.1 Cost-Benefit Analysis: Economic approaches are considered as an alternative when designing and implementing Smart home services. Economic approaches involve the analysis and optimization of the production, distribution, and consumption of goods and services. The approaches aim to analyze how home technologies economies work and how smart home entities interact economically

Cost-Benefit Analysis (CBA) is a common tool used to provide criteria for investment decisions making by comparing the benefits with the costs over the life span of a project. It is a method to estimate an equivalent money value in terms of benefits and costs from smart systems and services. CBA involves computing the benefits against costs for the entities to make decisions, for example, whether the system and service should be implemented or not, which technology and design should be adopted, and what the risk factors are (Niyato, 2016).

At the simplest level, CBA has three major components (IRENA, 2015):

- Estimation of the benefits of Energy Efficiency technologies. CBA focuses on the benefits related to smart homes and home Energy management systems; however, the other potential co-benefits are addressed as well. 
- Estimation of the costs of Energy Efficiency technology. This guide focuses on hardware and software costs, installation costs and ongoing operations and maintenance costs.

- Comparison of costs and benefits. Some costs and benefits, such as upfront hardware costs, are straightforward to quantify. Others, such as providing consumers with greater information and control or comfort, certainly have some value, but are extremely difficult to attach a monetary value to. We call these qualitative benefits.

CBA first determines the possible projects, designs, and their stakeholders. The metrics and cost/benefit elements are defined and calculated. CBA is developed through sub sequent steps as follows (Becchio, 2016):

1) Define project;

2) identification of costs and benefits of the project;

3) estimation of the monetary values;

4) distribution of the estimated costs and benefits over the time and construction of the cash flow;

5) definition of the discount rate;

6) calculation of the performance indicators. With specific reference to the performance economic indicators, these are represented by the Net Present Value (NPV) and the benefit/cost ratio (B/C). 
Net present value is nothing but sum net off of the present value of cash inflows and outflows by discounting the flows at a specified rate. The NPV was computed using next Equation (Enongene, 2017):

$$
\begin{aligned}
& N P V=\sum_{0}^{t} \frac{B_{t}-C_{t}}{(1+r)^{t}} \\
& \text { where: } \\
& B_{t}=\text { the benefit at time } \mathrm{t}, \\
& C_{t}=\text { the cost at time } \mathrm{t} \text {, and } \\
& \mathrm{r}=\text { the discount rate }
\end{aligned}
$$

As seen in the formula - To derive the present value of the cash flows we need to discount them at a particular rate. This rate is derived considering the return of investment with similar risk or cost for the investment (Enongene, 2017).

Lighting controls enable residents to use artificial light depending on the requirement, using lighting control products helps in saving certain units of electricity. Automated HVAC products also help to reduce the electricity consumption to a considerable extent. Several service providers and homeowners testify that home automation systems deliver substantial gains, thereby reducing the amount of energy wasted and also the costs incurred.

The applied scenarios of lighting control are as follows (Ringel, 2019):

Baseline: Lighting is controlled manually by family members who turn off the lights during vacation periods. A traditional thermostat with a fixed set point controls heating and cooling. 
Extended control project: Lighting is controlled by motion sensors that detect human presence. Daylight harvesting is provided, modelled through sensors that interface with the smart lamp.

We integrated motion and light sensors in the scenarios, the former being the most commonly used type. These are designed to detect the presence or absence of people in a room, and so offer finer scheduling granularity than predefined calendar and day settings. Light sensors allow lighting systems to respond to available light conditions.

Map Functions to Benefits:

- Improving energy efficiency and electric energy consumption reduction

- Annual electricity consumption bailing rate reduction

- Automated light switching

- Daylight harvesting and health benefits

- Environmental benefits and reduction of GHG emissions.

- Improve Indoor comfort and life quality raising occupants' satisfaction level

\section{Costs:}

- Up-front hardware costs. Also called capital or initial costs, these expenses are one-time costs associated with purchasing the specific technologies. 
Journal of Environmental Sciences (JES)

Faculty of Graduate Studies and Environmental Research, Ain Shams University

AbdulKarim. et al.

- Project implementation costs. These costs are associated with installation, programming, scheduling, project management, commissioning, and other cost components of project implementation.

- Operating and maintenance costs. These expenses are ongoing.

- Qualitative costs. These various expenses are difficult to quantify yet still relevant to the analysis. Qualitative costs can include management time and attention, risks associated with going over budget or with technical underperformance, and other similar factors that are difficult to assign a monetary value. For example, some users may have a cost of decreased building occupant comfort.

\section{SOWT Analysis:}

A holistic view of energy stakeholders in a strengths, weakness, opportunities, and threats (SWOT) perspective for Improving Energy Efficiency. SWOT analysis is based on the themes of market resources, energy technology and energy efficiency. With this analytical frame work, This paper lists the strengths and opportunities while compensating weakness and mitigating threats. The action portfolio is directed towards enabling sustainable development and stresses the importance of comprehensive energy strategy towards building a strong economic profile while minimizing carbon footprint including energy efficient systems for residential household. 
When performing a SWOT analysis, it is essential to define internal and external factors clearly before carrying out the analysis. Strengths are positive aspects that are controlled by stakeholders, whereas opportunities are possibilities due to external factors that could reduce weakness and improve on strengths, while threats are external factors that could harm or pose problems to stakeholders or Environment either in short term or long terms (Venkatachary, 2017).

Fig. 5. Summarizes SWOT analysis to diagnose and identify economic, social and environmental impacts from energy efficiency technologies. The results summarize and conclude that Improving Energy Efficiency technologies can be modelled to reduce costs, bring down carbon emissions and hence help protect the environment and improve quality of life with weakness in high initial installation cost with security and privacy concerns. 
Journal of Environmental Sciences (JES)

Faculty of Graduate Studies and Environmental Research, Ain Shams University

AbdulKarim. et al.

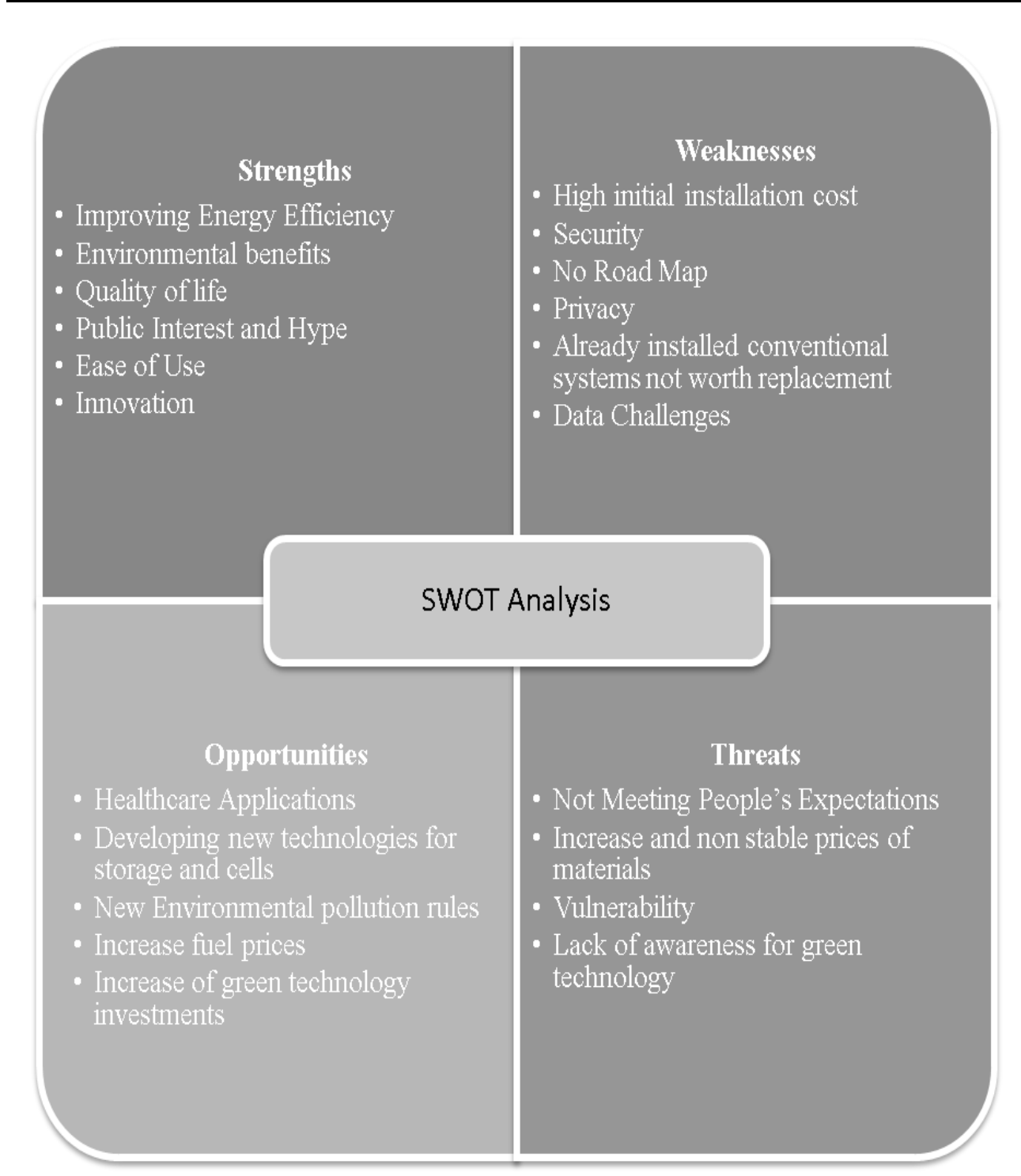

Fig. 5. SWOT analysis (Venkatachary, 2017). 
Journal of Environmental Sciences (JES)

Faculty of Graduate Studies and Environmental Research, Ain Shams University

AbdulKarim, et al.

\section{CONCLUSION}

Energy efficiency is the measure of energy services delivered relative to energy input. Improving Energy efficiency is gained when more energy services are delivered for the same energy input, or the same amount of services are delivered for less energy input.

In this work, the advantages of energy efficiency are well reported, with positive impacts on society, the environment, health and the economy. In the context of the societal challenges connected to the environmental questions, realizing improving energy efficiency is a topical issue. The domestic sector has been identified as one of the most promising ones, because of its high energy demand and its high potential for saving. Energy-efficient technologies and solutions can offer one of the most cost-effective ways of reducing energy costs, improving energy security, reducing local air pollution and mitigating climate change.

Some existing technologies initiatives have investigated the use of embedded systems and sensors to realize energy saving at residential sector. This thesis has focused on providing the analysis of the technologies with which used to build some system applications for improving energy efficiency and enhancing the quality of life. A great deal of emphasis is given to the sensor technologies that are the back bone of these systems. A brief analysis on the communication technologies which form the communication infrastructure for the Smart Home is also illustrated. 
Furthermore, this work described the integration between these technologies with sensors and embedded systems.

This paper also highlighted some other challenges and future directions that need to be addressed regarding energy management systems and Internet of things. It can be concluded that the area of building energy metering and indoor environmental technologies has witnessed many technological advancements in recent years, and it will be continued because of the developments in information and communication technologies.

\section{REFERENCES}

Ahmad MW, M Mourshed, (2016). Building energy metering and environmental monitoring - A state-of-the-art review and directions for future research, Energy and Buildings pp. 85-102.

Alahakoon Damminda, Xinghuo Yu, Smart Electricity Meter Data Intelligence for Future Energy Systems: A Survey, IEEE Transactions on Industrial Informatics, Vol 12, No. 1, (2016) pp. 425-436.

Asare-Bediako B., Ribeiro, P. F., \& Kling, W. L. Integrated Energy Optimization with Smart Home Energy Management Systems, 3rd IEEE PES Innovative Smart Grid Technologies Europe (ISGT Europe) Berlin (2012) pp. 1-8.

Asare-Bediako B., W. L. Kling; P. F. Ribeiro.Home Energy Management Systems: Evolution, Trends and Frameworks. 47th International Universities Power Engineering Conference, London (2012) pp. $1-5$. 
Atzori Luigi, Antonio Iera, Giacomo Morabito. Understanding the Internet of Things: definition, potentials, and societal role of a fastevolving paradigm. Ad Hoc Networks 56 (2017)

Barai G. R., Krishnan, S., \& Venkatesh, B. Smart Metering and Functionalities of Smart Meters in Smart Grid - A Review, IEEE Electrical Power and Energy Conference (EPEC). (2015) pp. 138-145.

Baronti P., P. Pillai, V. W. C. Chook, S. Chessa, A. Gotta, and Y. F. Hu, Wireless sensor networks: a survey on the state of the art and the 802.15.4 and ZigBee standards, Computer Communications, vol. 30, no. 7 (2007) pp. 1655-1695.

Becchio Cristina, S. P. Corgnati, Marta Bottero. Cost Benefit Analysis and Smart Grids projects. Conference: SBE16 TOWARDS POSTCARBON CITIES (2016).

Calvillo C.F. n, A.Sánchez Miralles, J.Villar, Energy management and planning in smart cities, Renewable and Sustainable Energy Reviews 55 (2016) pp. 273-287.

Choi T.-S., Ko, K.-R., Park, S.-C., Jang, Y.-S., Yoon, Y.-T., \& Im, S.-K. (2009) Analysis of Energy Savings using Smart Metering System and IHD (In-Home Display), Choi, T.-S., Ko, K.-R., Park, S.-C., Jang, Y.-S., Yoon, Y.-T., \& Im, S.-K. Transmission $\&$ Distribution Conference \& Exposition: Asia and Pacific. pp. $1-4$.

Coskun, V., Ozdenizci, B. \& Ok, K. (2013). A Survey on Near Field Communication (NFC) Technology. Wireless Personal Communications. Issue 3

Dorsemaine B., Gaulier, J.-P., Wary, J.-P., Kheir, N., \& Urien, P. Internet of Things: A Definition \& Taxonomy. 9th International Conference on Next Generation Mobile Applications, Services and Technologies (2015). 
Dragomir Dan, Laura Gheorghe, Sergiu Costea and Alexandru Radovici. (2016). A Survey on Secure Communication Protocols for IoT Systems International Workshop on Secure Internet of Things

Electrical4U, Watt Hour Meter. Retrieved on 20 December 2019 from https://www.electrical4u.com/watt-hour-meter

Enongene K.E., P. Murray, J. Holland, F.H. Abanda. Energy savings and economic benefits of transition towards efficient lighting in residential buildings in Cameroon. Renewable and Sustainable Energy Reviews 78 (2017) pp. 731-742.

Finkenzeller Klaus, RFID Handbook: Fundamentals and Applications in Contactless Smart Cards and Identification. John Wiley \& Sons, Ltd. Third Edition (2003).

García CG, D Meana Llorián, (2017). A review about Smart Objects, Sensors, and Actuators. International Journal of Interactive Multimedia and Artificial Intelligence (2017).

Ghodake Rupali, Sangeeta Jogade, Deepak Misal. Bluetooth Technology: An Overview. International Journal of Scientific Research in Computer Science, Engineering and Information Technology (2018).

Gurkan Tuna, Dimitrios G., Kogias b, V. Cagri Gungor. (2017). A survey on information security threats and solutions for Machine to Machine (M2M) communications. Journal of Parallel and Distributed Computing Volume 109 (2017).

Horton J. S., Prince, B., Sasson, A. M., Wynne, W. T., Trefny, F., Cleveland, F., \& Robinson, J. T. Advances in Energy Management Systems, IEEE Power Engineering Review (1986) pp. 226-234.

Hydro One, Getting Smart about Smart Meters Answer Book, Ontario, 2013. 
IEA (International Energy Agency), Energy Efficiency 2018 - Market Report, Analysis and outlooks to 2040, OECD/IEA. https://www.iea.org/efficiency2018/ Paris, 2018.

IRENA 2015, Smart Grids and Renewables: A cost-benefit analysis guide for developing countries. https://www.irena.org/publications/2015/Oct/Smart-Grids-andRenewables-A-cost-benefit-analysis-guide-for-developingcountries

IRENA 2018, Renewable Energy Outlook: Egypt, International Renewable Energy

Agency. https://www.irena.org/publications/2018/Oct/RenewableEnergy-Outlook-Egypt

Kara S., G Bogdanski,Electricity metering and monitoring in manufacturing systems, Glocalized solutions for sustainability in Manufacturing (2011) pp 1-10.

Kocakulak Mustafa and Ismail Butun. An Overview of Wireless Sensor Networks Towards Internet of Things, IEEE 7th Annual Computing and Communication Workshop and Conference Las Vegas, NV (2017) pp. 1-6.

Kumar C. R., Aziza Ibrahim. Kumar,VLSI design of energy efficient computational centric smart objects for IoT. Learning and Technology Conference (L\&T) Jeddah (2018) pp. 129-138.

Lamba Anil, Satinderjeet Singh, Balvinder Singh, Natasha Dutta. Mitigating IoT Security and Privacy Challenges Using Distributed Ledger Based Blockchain (Dl-BC) Technology, International Journal for Technological Research in Engineering Volume 4, Issue 8 (2017)

Liu Y, B Qiu, X Fan, (2016) - Review of Smart Home Energy Management Systems, Energy Procedia pp. 504-508. 
Miao Wu, Ting-Jie Lu, Fei-Yang Ling, Jing Sun, \& Hui-Ying Du. Research on the architecture of Internet of Things. 3rd International Conference on Advanced Computer Theory and Engineering (2010).

Niyato, D., Lu, X., Wang, P., Kim, D. I., \& Han, Z. Economics of Internet of Things: an information market approach. IEEE Wireless Communications. (2016).

Opher A., A. Onda, A. Chou, and K. Sounderrajan, The rise of the data economy: driving value through internet of things data monetizationIBM Corporation, Somers, NY, USA (2016).

Patel KK, SM Patel, Internet of Things-IOT: Definition, Characteristics, Architecture, Enabling Technologies, Application \& Future Challenges. International journal of engineering Science and Computing, (2016)

Perera C., Zaslavsky, A., Christen, P., \& Georgakopoulos, D. (2014). Context Aware Computing for The Internet of Things: A Survey. IEEE Communications Surveys \& Tutorials, 16(1) (2014).

Ringel Marc, Roufaida Laidi, and Djamel Djenouri. (2019). Multiple Benefits through Smart Home Energy Management Solution - A Simulation-Based Case Study of a Single-Family-House in Algeria and Germany. Energies 2019, 12, 1537.

Saeid Mohammad, Mahdavinejad, Mohammadreza Rezvan.Machine learning for the Internet of Things data analysis: A survey. Digital Communications and Networks (2017).

Said O. and M.Masud, Towards internet of things: survey and future vision, International Journal of Computer Networks, vol. 5, no. 1 (2013) pp. 1-17.

Serra Jordi, David Pubill, Angelos Antonopoulos, and Christos Verikoukis. Smart HVAC Control in IoT: Energy Consumption 
Minimization with User Comfort Constraints, The Scientific World Journal (2014)

Shanker, Akshay and Stern, David I., Energy intensity, growth and technical change. CAMA Working Paper No. 46/2018 (2018).

Simonov Mikhail (2014), Hybrid Scheme of Electricity Metering in Smart Grid, IEEE Systems Journal, Vol. 8, No. 2, pp. 422-429.

Sundaram Shanmuga B., (2016). A Quantitative Analysis of 802.11 ah Wireless Standard. International Journal of Latest Research in Engineering and Technology, vol. 2 (2016).

Suresh P., Daniel, J. V., Parthasarathy, V., \& Aswathy, R. H. (2014). A state of the art review on the Internet of Things (IoT) history, technology and fields of deployment. International Conference on Science Engineering and Management Research -(ICSEMR) (2014).

Uckelmann Dieter, Mark Harrison, Florian Michahelles. (2011). Architecting the Internet of Things, Chapter 1. Berlin pp. 1-24.

UN (2018) Sustainable Development Goals Report, https://unstats.un.org/sdgs/report/2018

Uribe-Pérez Noelia, Luis Hernández, David De la Vega, State of the Art and Trends Review of Smart Metering in Electricity Grid, Applied Sciences 6(3) (2016) pp. 68-92

Venkatachary S. K. Jagdish Prasad, Ravi Samikannu. Application of Strengths, Weakness, Opportunities, and Threats Analysis in Smart Grid - Virtual Power Plant for Sustainable Development in India and Botswana. International Journal of Energy Economics and Policy (2017).

Yang SH. (2014). Internet of Things. In: Wireless Sensor Networks. Signals and Communication Technology. Chapter 12 pp. 247-261. 
Yang, D., \& Ren, H. The research on the technology of Internet of Things and embedded system. 8th IEEE International Conference on Software Engineering and Service Science (ICSESS) Beijing (2017) pp. 395-398.

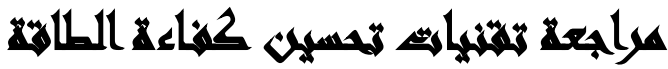

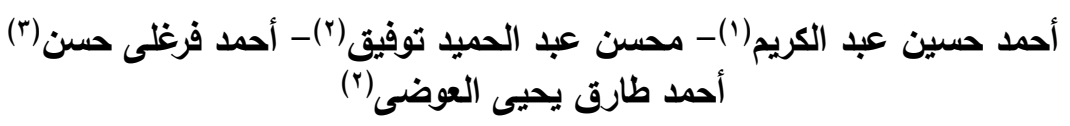

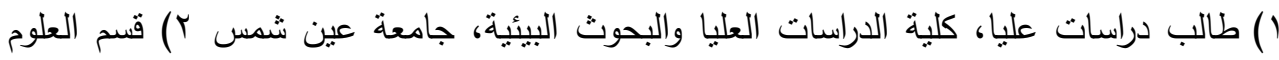

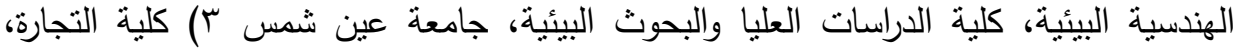

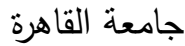

\section{كم:}

يشكل استهلاك الطاقة وتوليدها بكفاءة عاملا رئيسيا في تحقيق الأهداف الطموحة للتنمية

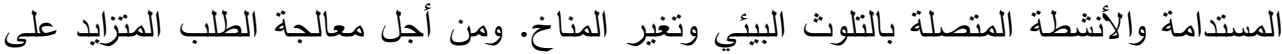

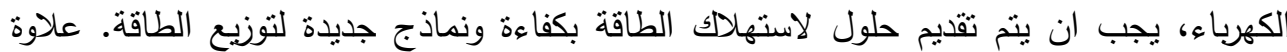

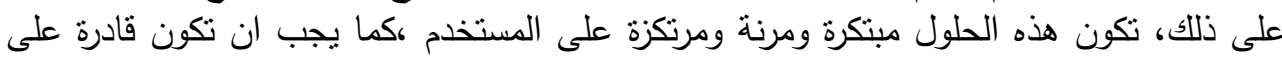
رصد الطاقة التفاعلية، وتحقق التحكم الذكي و موازنة الطلب على الطاقة في المنازل السكان السكنية. ويقترح هذا البحث منهجا فعالا من حيث التكلفة وتوفير الطاقة لتحسين كفاءة الاستخدام والتحكم في الأجهزة المنزلية باستخدام المنظومات المدمجة المعتمدة على المتحكم الدقيق. ويشمل

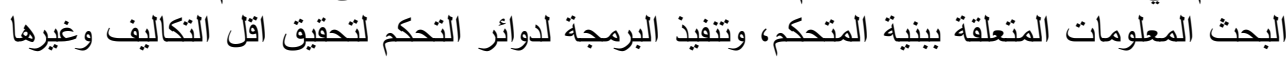

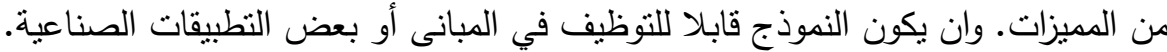

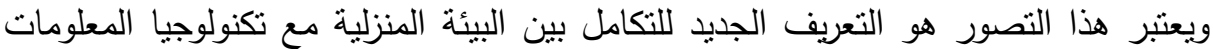

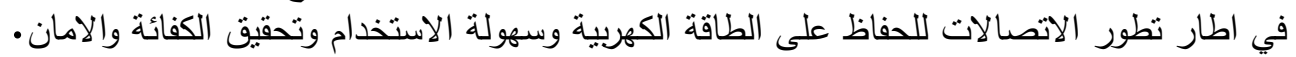
الكلمات الدالة: كفاءة الطاقة - المنزل الذكى -انترنت الأشياء الطياء 